\title{
Two-Dimensional Radiation-Hydrodynamic Calculations for a Nominal 1-Mt Nuclear Explosion Near the Ground
}

\author{
Henry G. Horak \\ Eric $M$. Jol.es \\ Maxwell î. Sandford II \\ Rodney W. Whitaker \\ Bichard C. Anderson \\ John W. Kodis
}

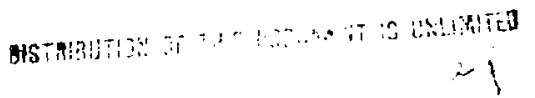
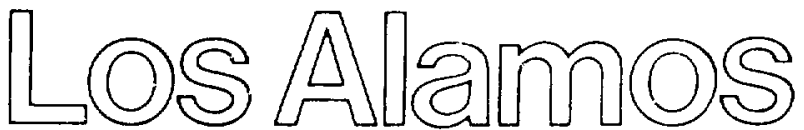

Los Alamos National Laboratory Los Alamos, New Mexico 87545 


\title{
TWO DIMENSIONAL RADIATION HYDRODYNAMIC CALCULATIONS FOR A NOMINAL I MINUCLEAR EXPLOSION NEAR THE GROUND
}

\author{
by \\ Henry G. Horak, Eric M. Jones, Maxuell T. Sandford II. Rodney W. Whitaker. \\ Richard C. Anderson, and John W. Kodis
}

\begin{abstract}
The two dinensional radiation hydrodynamic code SN YAQLI was used to calcu late the esolution of a hypothetical nuclear fireball of I Mt yield at a burst altitude of $500 \mathrm{~m}$. The ground reflected shock wave interacts strongly with the fireball and induces the early formation of a rapidly rotating ring shaped wortex. The hydrodynamic and radiation phenomena are discussed.
\end{abstract}

\section{INTKODUCTION}

In Ret. 1. J. Zinn describes the one dimensional radration hydrodynamic code RADPl.O and presents an application of his method of calculating the erolution of a hypothetical $1 \mathrm{Ml}$ vield nuclear firebiall. Because two dimensional effects become important when the fireball is close to the ground. we have extended his calculations into two dimensions by treating a I Mt burst at an altitude of $500 \mathrm{~m}$. We applied the computer program SN YAQUI, a variant of YOKIFER (described in Refs. 2. 3. and 4!. SN Y AQUI was especially designed to be consistent with RADFLO and the same 40 frequency groups, opacity and equation of state tables for air used by Zinn are incorporated into this code.

SN.YAQUi is written in $r \cdot z$ cylindrical geometry and performs, in alternate seps. two nain functions: (1) hydrodynamic evolution i; followed in Lagrangian fashion with the code YAQ Jl (Ref. 5), and (2) radiative evolution is followed with a simplified version of the code TWOTRAN (Ref. (1). Which is based on the method of discrete ordinates (or SN). Whenever necessary, an automatic particle-in- ell rezoning procedure ${ }^{7}$ is carried out to prevent cell buundaries from becoming concave; temporary rezones also are performed regularl'y for the
SN. Which reyures colfs of rectanguiar crose nectum. Provinion in made for the reflection of light from the ground surface in accordance with Lambert law of diffuse reflection with a given albedo, to whoch at alue ait unity uas assigned for the calculatwon reported here.

The initial conditions are obtained at an appropratic cholution tume by adonting values of the physical patram eters derived from RADFLO: the time chosen $(0.1$ it 1 . just before the shock strikes the ground. The initial physical quantities are specific internal energy for $\mathrm{km}$ perature). density. and the radial and axial components of velucity (tigs. 1, 2, and 3). The values are interpolated from the RADFLO mesh containing $\sim 100$ spherseal zoner unto about half of the total $7000(70 \times 100)$ cell of the SN YAQUI mesh. For the problem at hand. the length of a ceil side averages $\sim 10 \mathrm{~m}$. In addition. a uniform distribution of some 250 massless marker particles is established within the fireball portion of the mesh (Fig. 4): these are moved with the instantaneou. fluid velocitics and serve as tracers for the debris material within the fireball. The values of the physical variables in ambient cells are set in accordance with a realistic mudel atmosphere consisting of the altitude profiles of pressure. temperature, density, and water vapor. 
At cenain preselected times. computer derived graphs of the firchall are generated. showing the physical varlables. isophotes. etc. In the following sections. we will discuss the shock wave. Mach stem, reflect ad shock fireball iriteraction. rise and growth of the fircball. and radiation held.

\section{THE SHOCK WAVE AND MACH STEM}

The promary shock wave originating from the detona tion strikes the ground shortly after 0.1 s. reflecis. and returns through the fireba!l (see Fig. 51. Compressive heating rasses the sound speed behund the shock and the propagation speed of the retected shock. Consequently. the Mach stem. the intersection surface of the two shocks, forms at the ground and with time increases vertically. Normaily, the propagation of the Mach stem is complicated bo the character of the terrain. by the ground shock. and sometumes by the presence of a near surface layer of healed air. Whuth can ciause a precursor shock to form. ihese ellects are not included in this calculation, wheh considers an ideal ground siriace. The reflected shock pastes through the hurst point at 0.24 s and merges completely with the primary snock at 1.0$)($ Fig. 6). The salculated rertical distances of the primary and reflected boeks and the horizb....l distance of the Mach sten from the ub detonation point are given as a function of time in $\mathrm{r}$-ig. $7 \mathrm{a}$. The altitude of the triple point vs time is shown in Fig. 7b. Figure 8 gives the relative peak overpressure. $\left.1 \mathrm{p}-\mathrm{p}_{0}\right) \mathrm{p}_{1}$, where $\mathrm{p}$ is the peak pressure in the Mach stem and $p_{0}$ is the ambient pressure. and the relative peak dynamic pressure. $q / p_{0}, \quad 0.5 \rho v^{2} p_{0}$, where $\rho$ is density and $v$ is velocity. A pressure cross section of the Mach stem at $0.6 .3 \mathrm{~s}$ is shown in Fig. 9. The calculated Mach stem doesn't display the sharpness or high peak pressure that could be produced by finer zoning is the Mach sten region.

\section{THE RING VORTEX, FLOW FIELD, AND FIREBALL RISE AND GROWTH}

A "free-air" nuclear burst has negligible interaction between the fireball and reflected shock; however. buoyancy forces deform the rising rireball and eventually create a ring vortex (toroid). When the interaction occurs early, as in the present case, the strong reflected shock imparts high negative yorticity to the fireball similar to that produced by buovancy (the upward veiocities near the $z$ axis are highest), and the ring vortex forms much earlier than :t would from buoyancy alune. For a $\mathrm{i}$ Mt free air burst. the time of toroid formation is $-11 \%$ but for a burst altitude of $500 \mathrm{~m}$. the calculated time is -1.5 s. The following situation occurs (see Fig. 10): a center of negative vorticity forms behind the reflected shock and. at 0.20 s. has tiven lo an altitude of $70 \mathrm{~m}$. By $0.375 \mathrm{~s}$. it hat migralled is $225 \mathrm{~m}$ : erentually it hecomes the toroidal vortex. Figure lla grues the altitudes of the vortex center and the firchall top and the horizontal radius of the firchail (1000 $\mathrm{K}$ isothernl during the first 7 s. Figure Ilth gives the horizonal anc vertical coordi nates of the vort"x conter for times to 70 s.

The fow lield near the lireball displays a predictable. though dramatic. hehavor. At fir the velocities are directed radialiy outwards bollind the prinary shock The reflected shock passes through mid firehall at 0.24 , with an accompanying updrall. The loroid is extabluhed by - 1.5 s: mean while. the primary chock and Mach stom continue to prese outward. though ever weanening the resoring procedure eventually discards them from the mesh. The regur ummediately athowe the promars sorten and lowards the a a dis display a strong positive wothe 1! (Fog. io) that was oreginaly created by an in ward mosing denturbance at $-(0.1 .3$, and is a man destation of inital condition obtained from R.ADF1.O.

As the firctall rives, the updraft along the 1 axs continues and pults in repiacement air from several kilometers anat. This creates the "afterwind" that charateristically observed in low altitude explosions." Vedocty profiles along the $z$ axis are shown in rig 12

The marker particles revolve about the internal coroid axis (Fig. I.3) with angular velocity during 1.5 to 4 s amounting to -2 rads and linear speed $-240 \mathrm{~m}$ relative to the wroid. which in turn rises at $-80 \mathrm{~ms} \mathrm{~s}$. B: $20 \mathrm{~s}$. the angular velocity of the ioroid has decreased to $-10 \%$ of its inital value.

\section{iV. RADIATION PHENOMENA}

The calculated radiative crolution of the firebull is carried out with the method of discrete ordinates. A: certain selected times. graphs are computer generated to show isophotes and irradiances in several spectral bands for a given observer's position. For this purpose. it is most convenien and accurate to apply the method of characteristic rays: the emergent radiances of the firebal! in the direction of the observer are obtained by the direct application of the formal solution to the equation of 
transler. The details are given in Ref. $y$.

Figure 14 shows the calculated emitted power of the lireball as a function of time summed over all wat elengthis and in the red ( $\lambda \lambda \lambda^{5} 600$ to $680(1)$ and areen (AAdhoO $655(0)$ A) band. These powers were computed by the SN method and are consistent with irradances determined independenty b: integrating wer radiances obtaind from characteristic rays. The integral of rad ated energ! taken ower the power time surve gives at "thermal traction" of the cutal seld atmountung to $2.0 \%$.

Figure 15 shous calculated sophoten ar the red wavelength hand at relected umess an would he obered from a positorn localled lorisontally $500 \mathrm{~km}$ from the fircball. Table 1 gises the maximum comperature in the mesh and the maxmum bre'tness temperature obtamed from the souphotes an the sisthe spestral region for

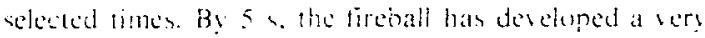
promiaient "skir." which in the larges hot. hut relatusly quiescent. region heneath the rapidy rotatune wornd. It arises als a consequence of the deformation of somberm produced by the reflected thock ifig. lof). Several calculated enntiluous spectria are hom in Fig. 17. Such

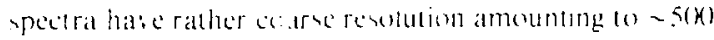

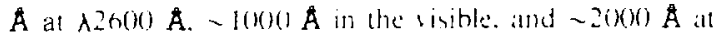
$\sim 1 \mu \mathrm{m}$.

TABLE 1. Maximum Temperatures In Mesh And Maximum Brighencos I amperature

\begin{tabular}{ccc}
$\begin{array}{c}\text { Time } \\
(\mathrm{s})\end{array}$ & $\begin{array}{c}\mathrm{T}_{1} \\
(\mathrm{~K})\end{array}$ & $\begin{array}{c}\mathrm{T}_{\text {R.un }} \\
(\mathrm{K})\end{array}$ \\
0.15 & & \\
6.20 & 39000 & 3800 \\
0.50 & .30000 & 7000 \\
0.75 & 18000 & 7800 \\
1.00 & 15000 & 7850 \\
1.25 & 12500 & \\
1.50 & 4600 & \\
2.00 & 8300 & \\
3.00 & 7100 & 6000 \\
6.00 & 5800 & 4900 \\
8.00 & 4800 & 3550 \\
10.00 & 4500 & 3.150 \\
\hline
\end{tabular}

\section{ACKNOWLEDGMENTS}

We wish to thank J. Zinn for valuable discussions. A. Amsden. R. Gentry, and H. Ruppel assisted us with the
YAQLI hy Irodynamos and $W$. Reed and $k$ I athrop assuted an implementung a smplified verson of the THOTRAN radiation tramsport frogram.

\section{RFIRENCES}

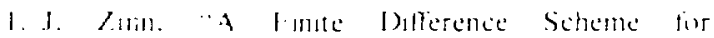
lime bependent Spbercial Radation Hubro

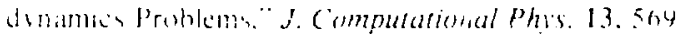
$119-3)$

2. R. L Andersm and M. I. Sandford II *YUKJFFR: A Tuo Domemonal Hedrotynames and Radatom Iranyport Program." low Alamou Scuentulic labora tort report LA S-64 MS (January 1475).

․ 11. I. Sandtord $I !$ and R. C. Anderion.

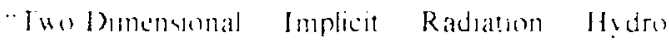
Jyentmos. A. Compuarional Phis. 13, 13011973).

4. M. T. Sandfors II. R. C. Anderom. H. G. Horak. and

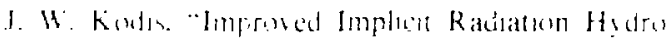
dyllam:心," I Compuational Phis. 19. 280119751

5. A. A. Amaden and $C$ W. Hirt. "A AQLA An Arbitrar! lagrangan Eulcran Compuler Program for Flund Flew al all Speeds." Los Alamos Scientilic

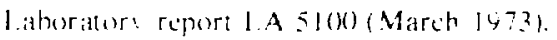

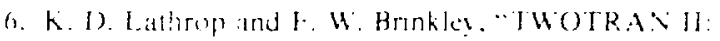
In Interlaced, feportable Verson of the TWOTRAN Code for TWo Dimensmal Tranpont." Lo Alamor Scientific laboratory report I.A 48一 MS (July 1973).

7. H. Horak IE M. Jones J. W Kodes and M I Sandford 11. "An Algorithm for the Discrete Rezon ing of Lagranglan Mewhes." J. Computarional Phis 26. $27:(19781$.

8. S. Glasstone. Fi.. The Effects of Vuclear Heapons. ulS Alomic Fnergy Commision. Rev. 1962). pp. 3.3.

9. H. (i. Horath and J. W'. Kodis. "Slant Path Distances Through Cell in Cylindrical Geometry and the Compulation of Isuphotes." to be published as a Los Alamos National Laboratory LA series report. 


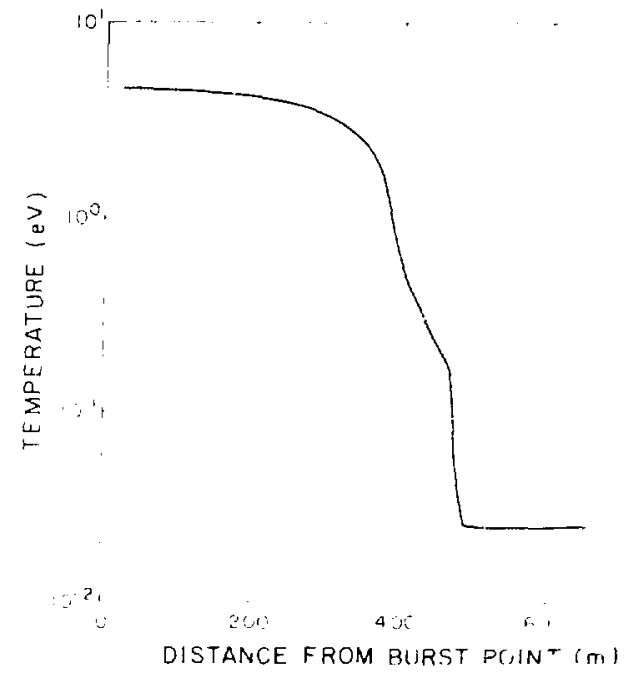

1 $i_{5}$. I. Intial temperature distribusion all 0.1 ,

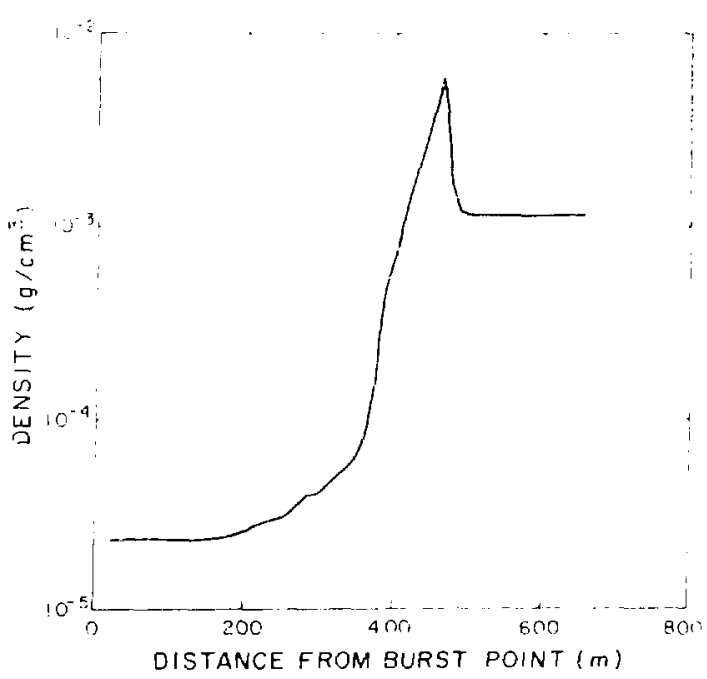

Fig. 2. Initial densily distributiun at 0.1 s.

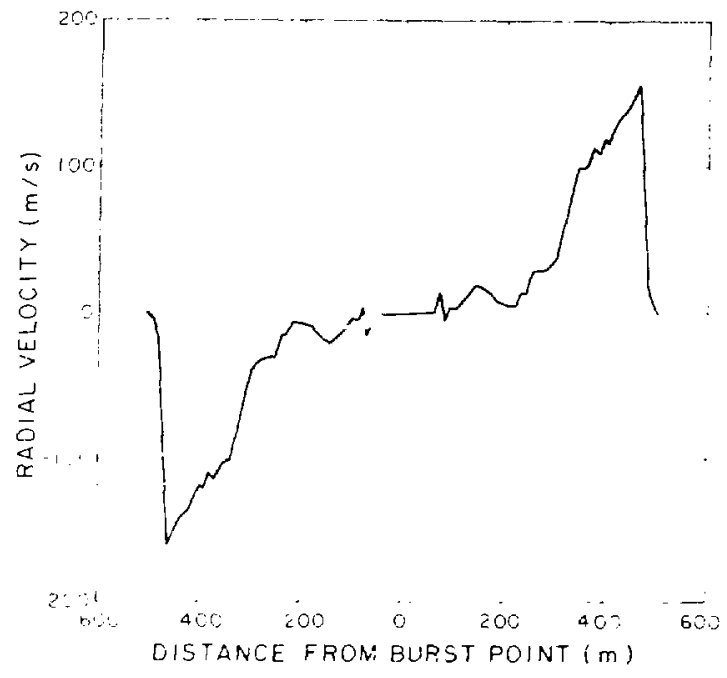

I ig. A. Inicial selocity distribution at $0.1 \mathrm{~s}$.

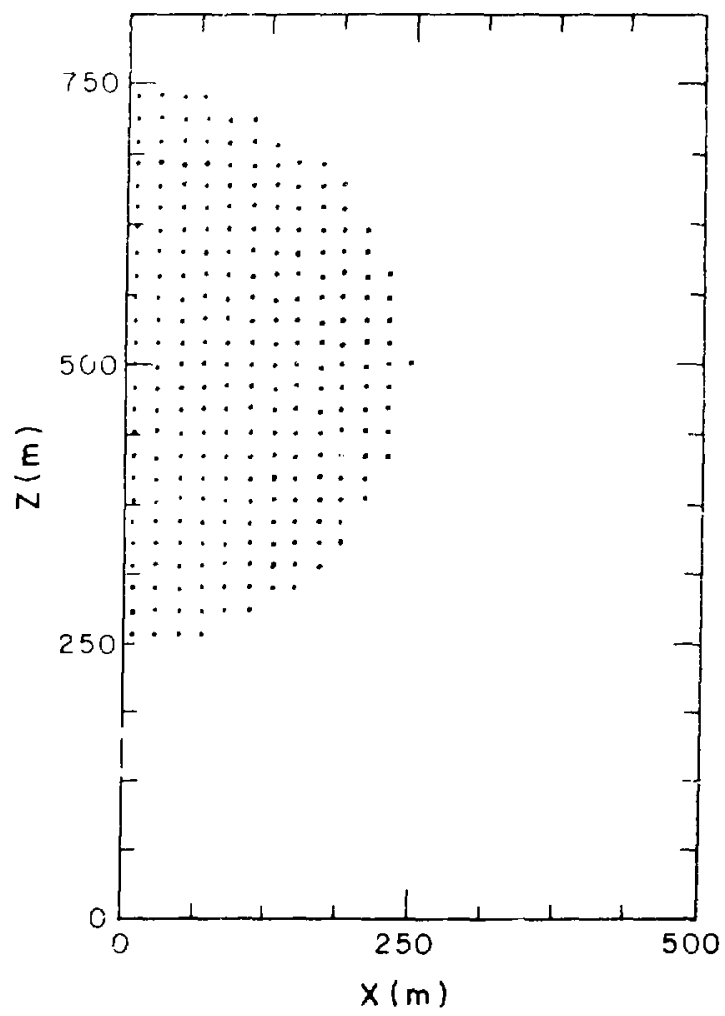

Fig. 4. Initial distributenn of Lagrangian particles in the vertical plane 1.) al 0.1 s. 


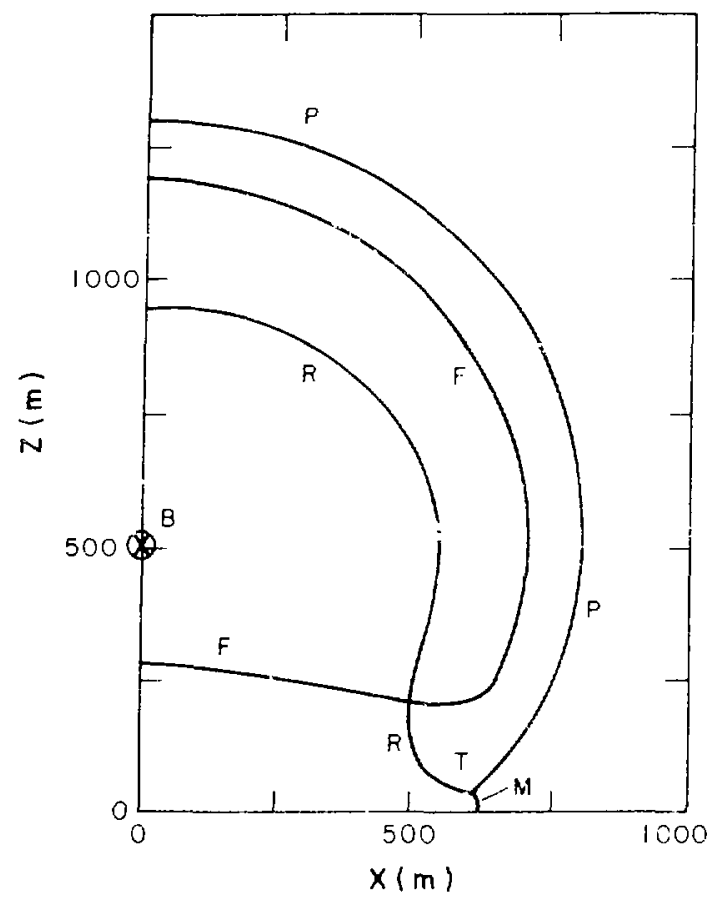

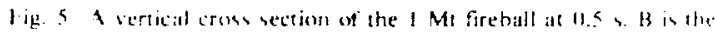

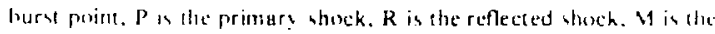
Mitch sem. I in the erpte pe: the atd $\mathrm{I}$ is the $3000 \mathrm{~K}$ isutherm.

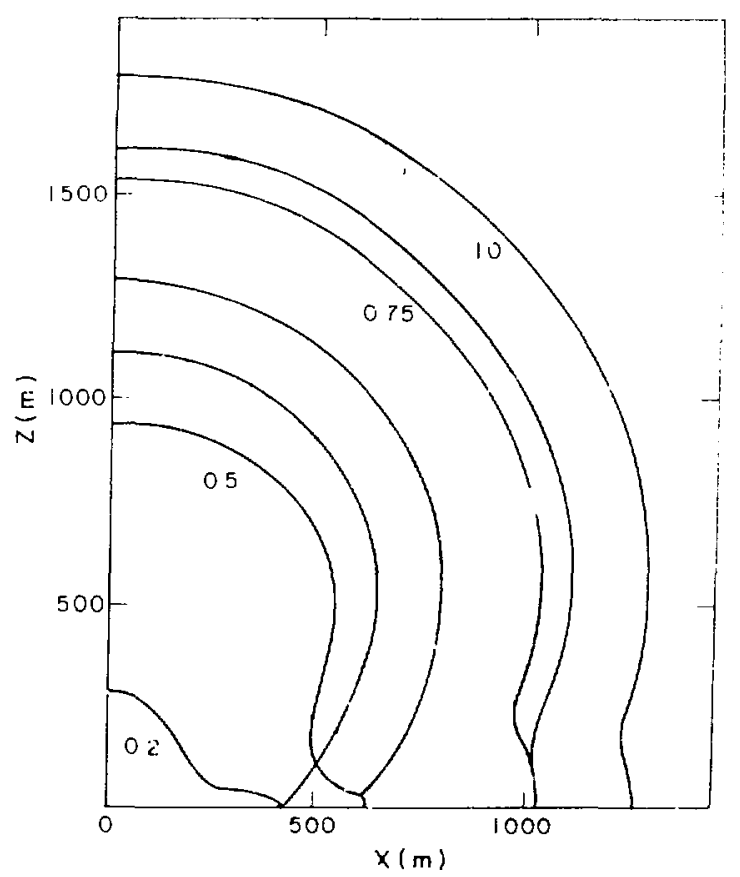

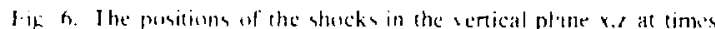
$0.2,0.5,0.75$, and 1.0 . 


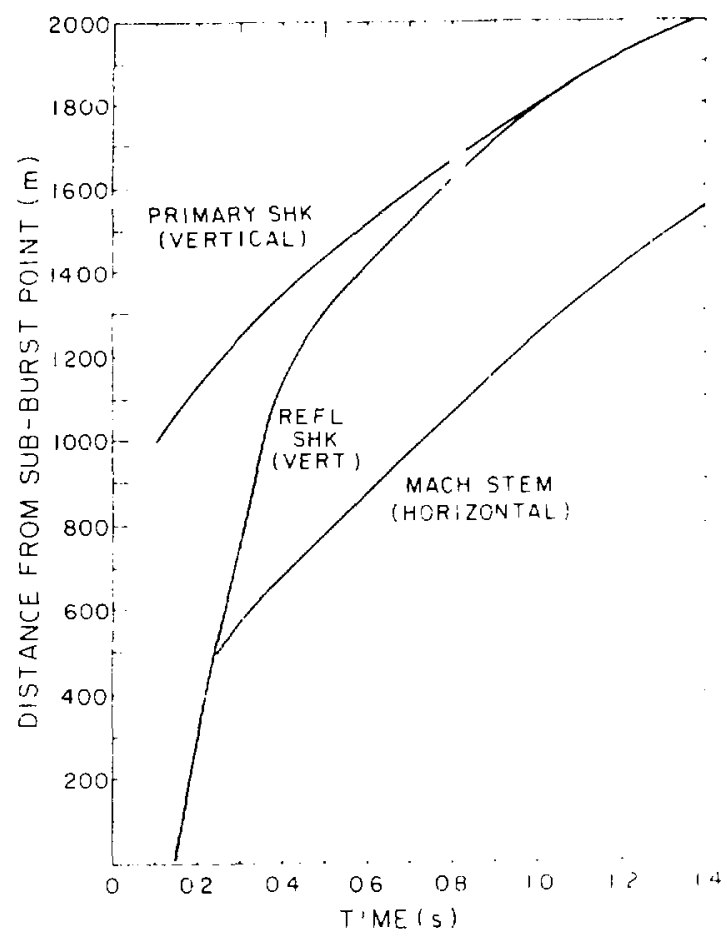

1.ig. 7a. The e ercicat distances of the primilrs and reflected shenk and the horizontal distance of the Macl, terre from the sub bar point as functions of thire.

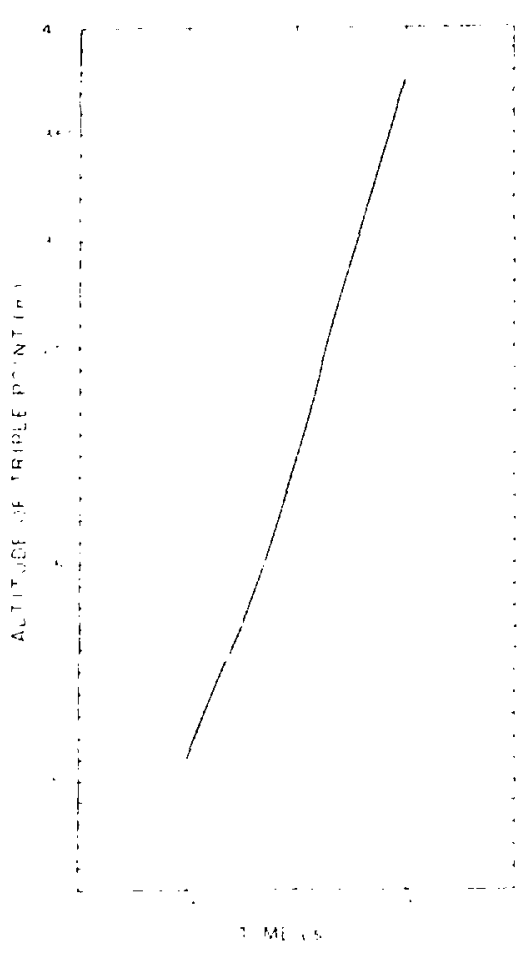

1 ري. Th. Allitude of the triple paint w time.

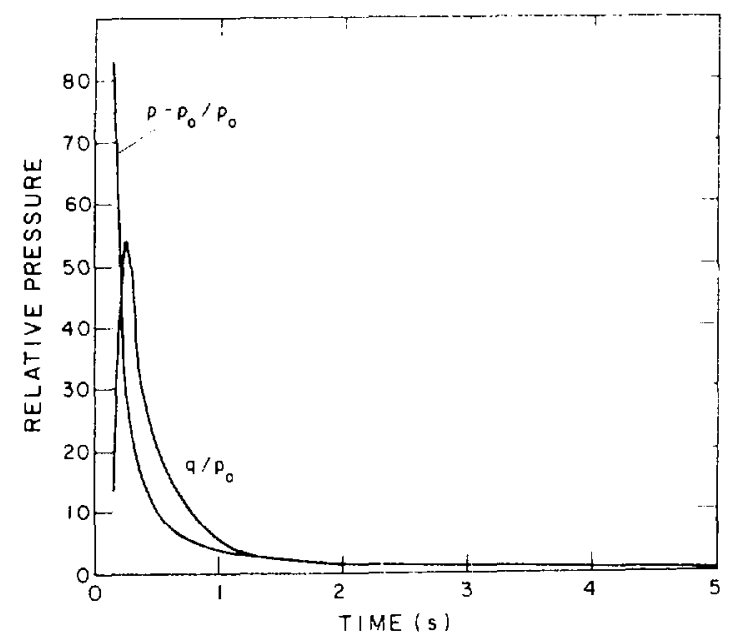

Fig. 8. The relative peak werpressure. (p $p_{0}$ l/p., und the reidive peak dynamic pressure. $4 / p$. in the Mach stem vs time. 


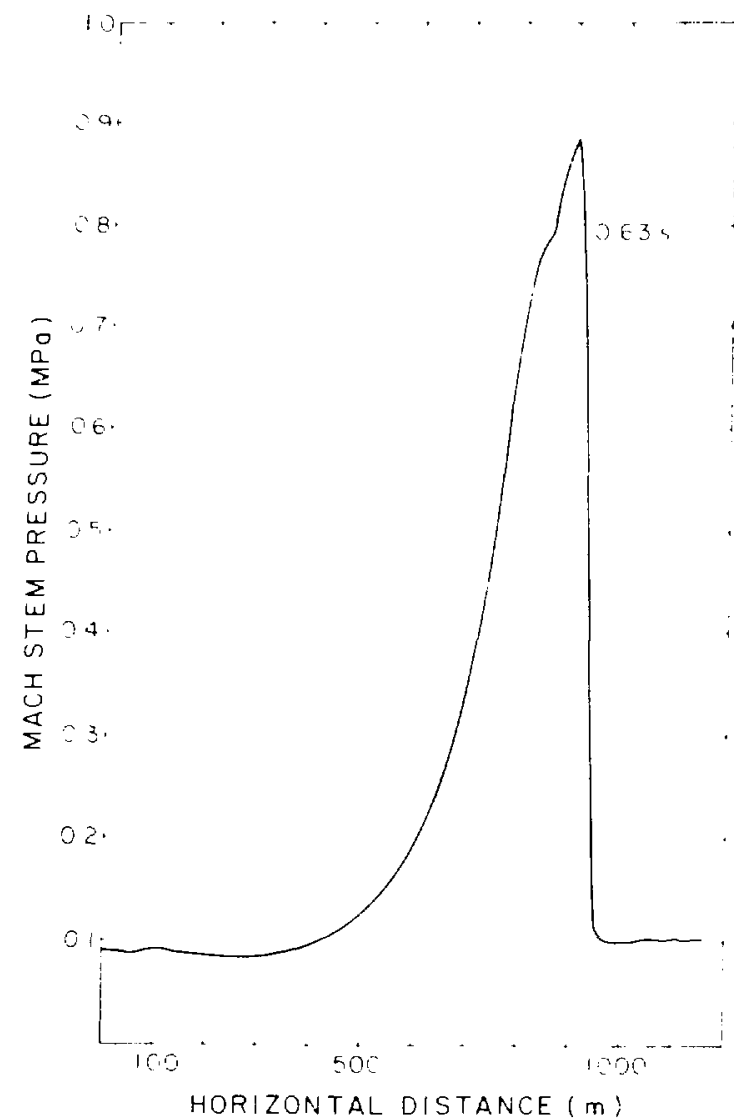

Fig. 10. A few isopleths of relative vorticits are shoun at $1.5 \mathrm{~s}$. Previous positions of he center of negative vorticits are indicated by $\therefore$ and of positive vorticity by .
Fig. Y. The nresure profile through the Wach stem at ground lesel at $0.6,3$.

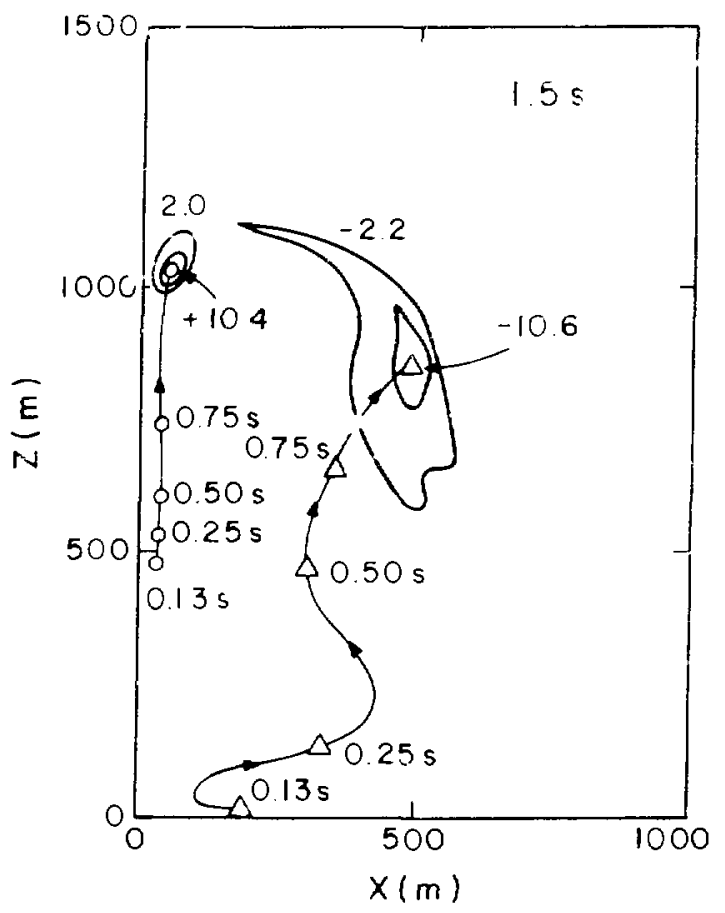




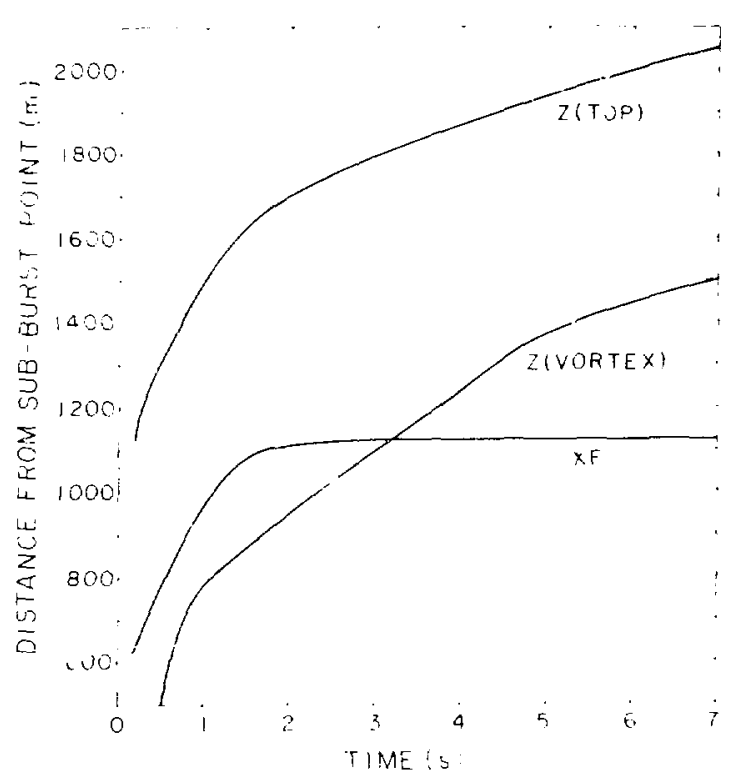

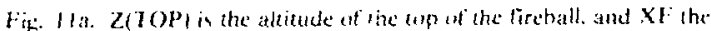

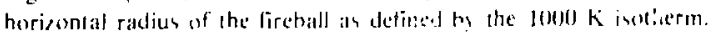

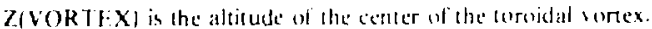

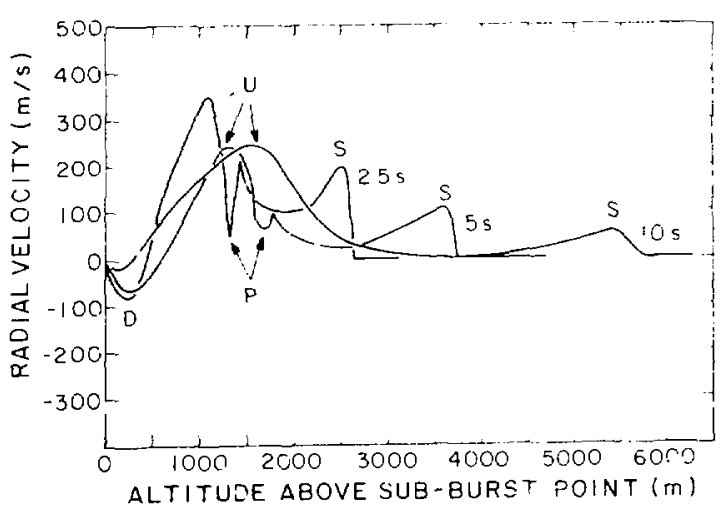

Fig. 12. Hadial velucity curses along the 1 in:m at 2.5 . 5. and ?0 4. The region of updraft is laheled $(i$, doundraft $D$, sheck 5 , and the small region of pomitise sorticity (Fig. 101 ) is litheled $P$.

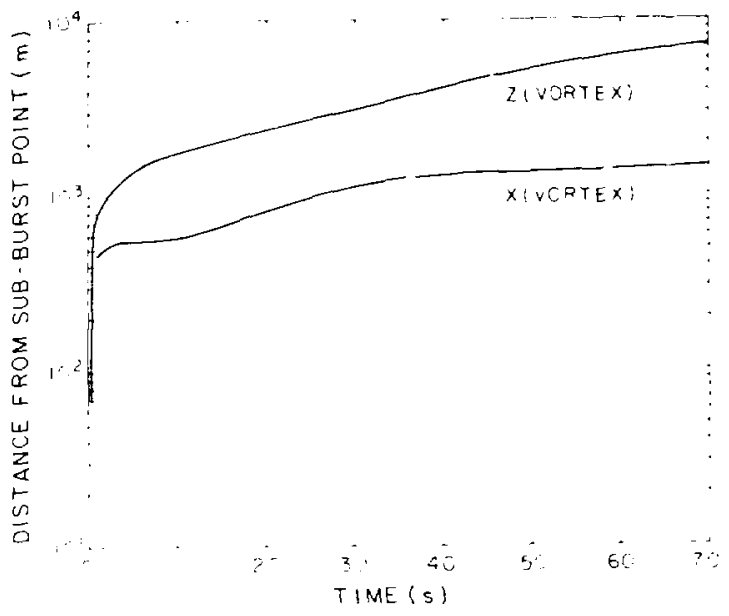

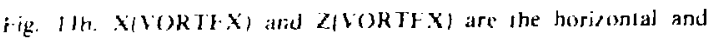
cortical consdinates of the center of the toroidal bortex.

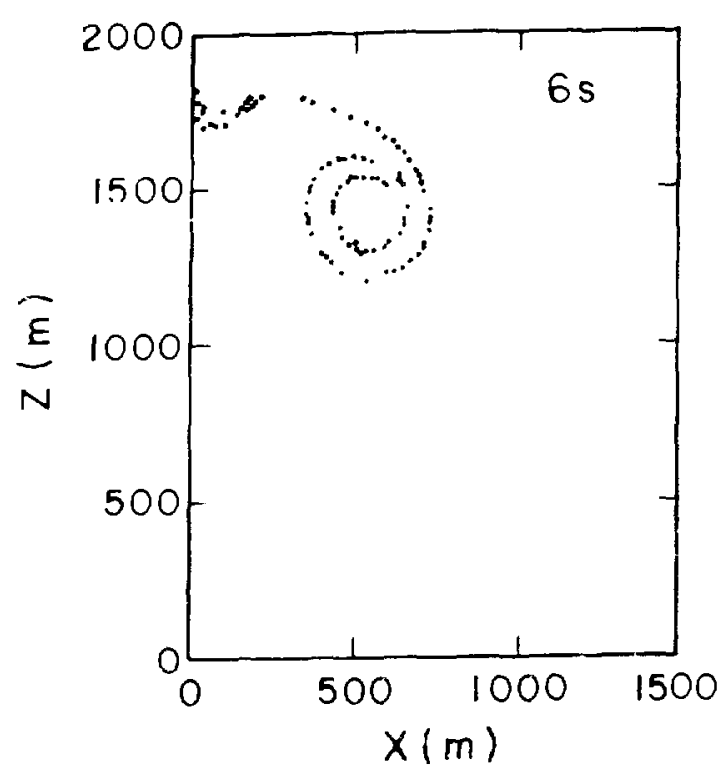

Jig. 1.3. Iagrangian marher particles at 64. 


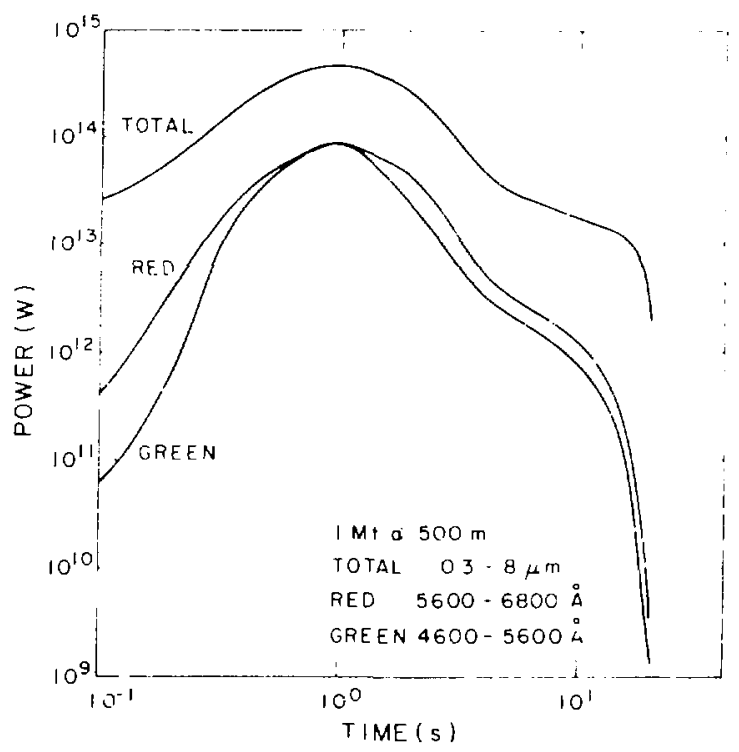

Fig. 14. Calculated emitted pouer of firebali as a furction of time integrated oser all bands (total) and for the red and green bands. 


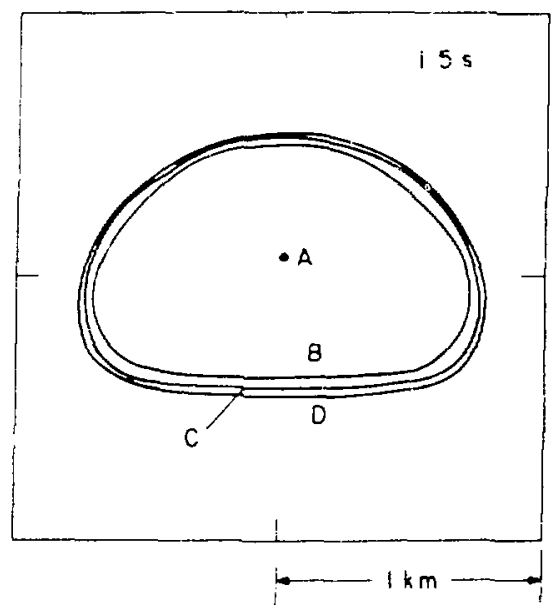

(a)

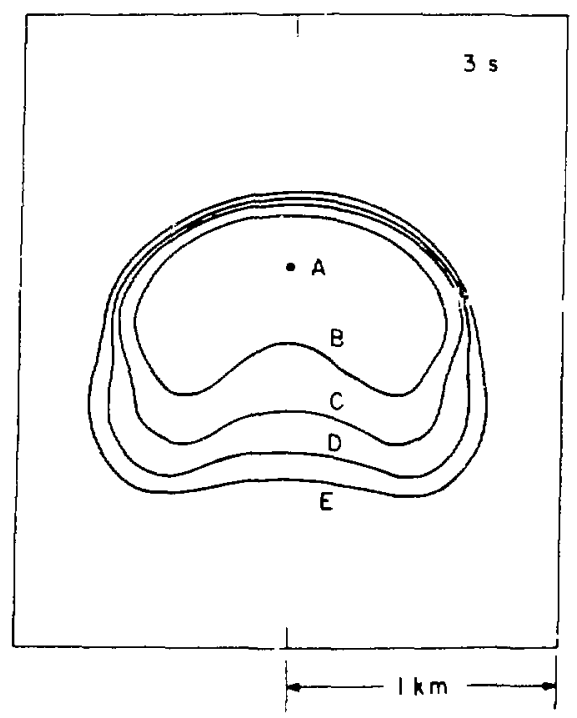

(b)

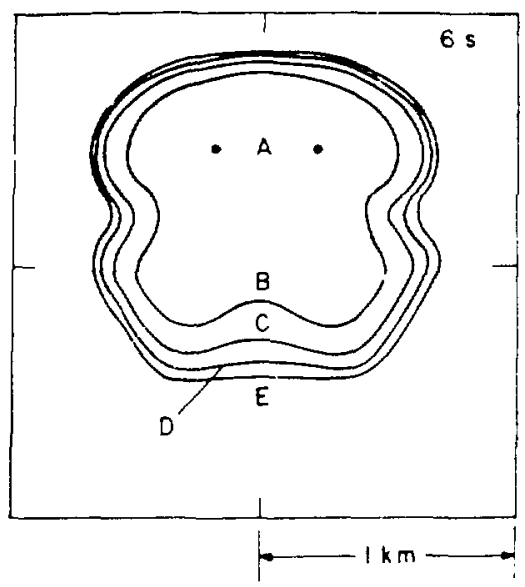

$|c|$

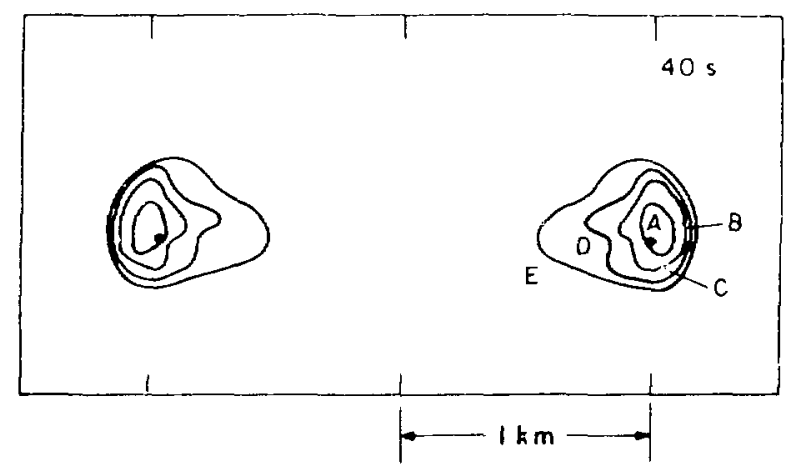

$|\mathbf{s}|$

F. 15. Isophoess in the red hand 15600106800 A) at selected times. The radiance factor betulen successive incphotes is 1 . 38 . The hrightest poines are marked ' A." 


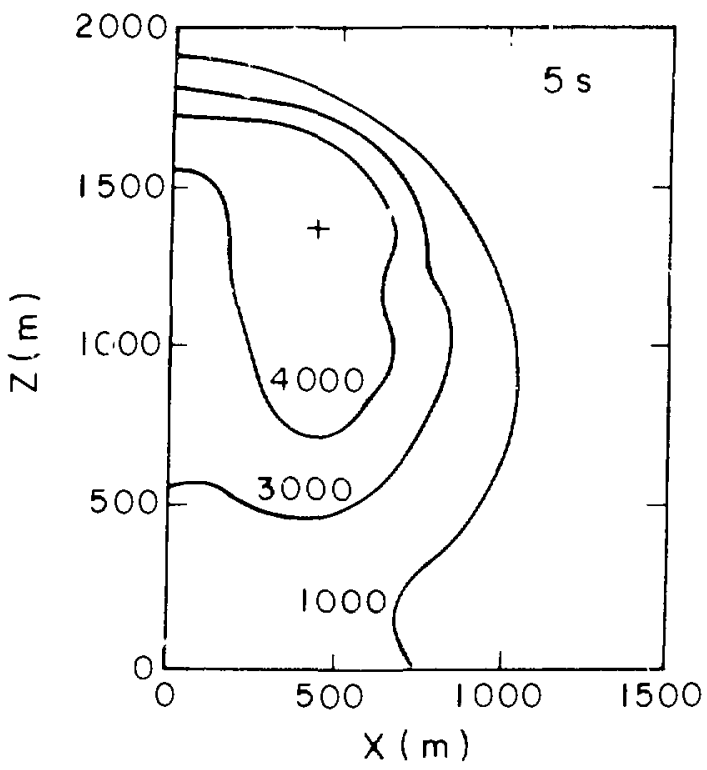

Fig. 16. Wotherms al: s. The center of the toroid is marked t.

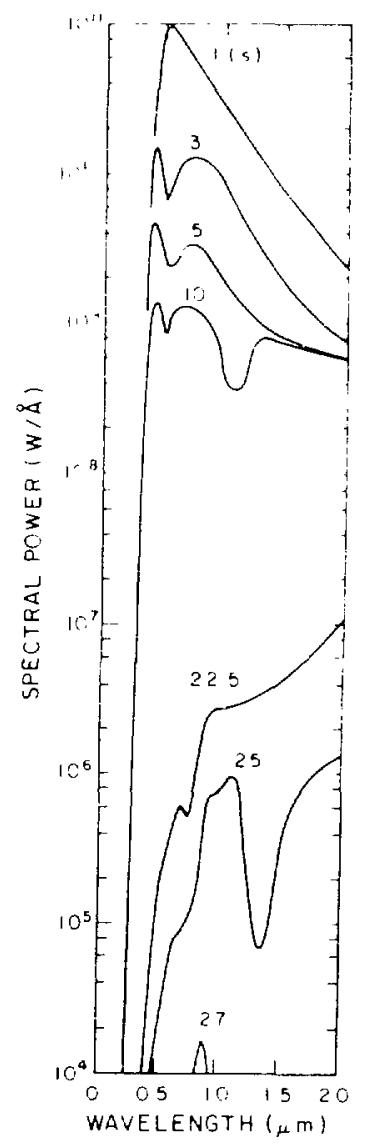

Fig. 17. Continuous spectra ot various times. 